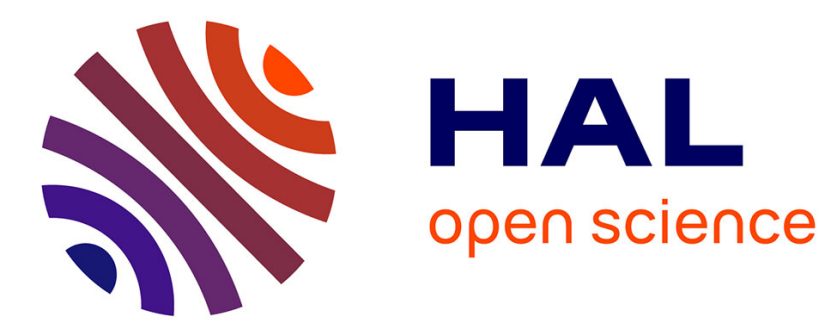

\title{
Effect of impact or shapes on the low velocity impact damage of sandwich composite plate: Experimental study and modelling
}

\author{
Ali Kurşun, Mehmet Şenel, Halil M. Enginsoy, Emin Bayraktar
}

\section{To cite this version:}

Ali Kurşun, Mehmet Şenel, Halil M. Enginsoy, Emin Bayraktar. Effect of impact or shapes on the low velocity impact damage of sandwich composite plate: Experimental study and modelling. Composites Part B: Engineering, 2016, 86, pp.143-151. 10.1016/j.compositesb.2015.09.032 . hal-01539115

\author{
HAL Id: hal-01539115 \\ https://hal.science/hal-01539115
}

Submitted on 24 Nov 2021

HAL is a multi-disciplinary open access archive for the deposit and dissemination of scientific research documents, whether they are published or not. The documents may come from teaching and research institutions in France or abroad, or from public or private research centers.
L'archive ouverte pluridisciplinaire HAL, est destinée au dépôt et à la diffusion de documents scientifiques de niveau recherche, publiés ou non, émanant des établissements d'enseignement et de recherche français ou étrangers, des laboratoires publics ou privés.

\section{(ㄷ)(1) $\$$}

Distributed under a Creative Commons Attribution - NonCommerciall 4.0 International 


\title{
Effect of impactor shapes on the low velocity impact damage of sandwich composite plate: Experimental study and Modelling
}

\author{
Ali Kurşun ${ }^{1,4}$, Mehmet Şenel ${ }^{2}$, Halil M. Enginsoy ${ }^{3}$, Emin Bayraktar ${ }^{4}$ \\ ${ }^{1}$ Department of Mechanical Engineering, Hitit University, Çorum, Turkey \\ ${ }^{2}$ Department of Mechanical Engineering, Dumlupinar University, Kutahya, TURKEY \\ ${ }^{3}$ Department of Mechanical Engineering, Uşak University, Uşak, Turkey \\ ${ }^{4}$ Supmeca - Paris School of Mechanical and Manufacturing Engineering, France
}

\begin{abstract}
An experimental and numerical analysis of the influence of impactor shapes on the low velocity impact performance of aluminium sandwich composite plates has been carried out. The aluminium composite panels were manufactured by using two aluminium sheets and a low density polyethylene core under heat and pressure, which shows the outstanding properties of low weight, good rigidity and impact resistance. Experimental tests were performed using drop weight test machine, samples were impacted using steel conical, ogival, hemispherical and flat impactors, all $12 \mathrm{~mm}$ in diameter, for different initial impact energies of $29.43 \mathrm{~J}$ and $44.15 \mathrm{~J}$ and specimen thickness of $4 \mathrm{~mm}$ containing three different parts $(0.5+3.0+0.5)$. A three dimensional non-linear finite element model is developed for simulating the impact behaviour of sandwich composite plate and the ABAQUS/Explicit commercial program was used. The face sheet material aluminium alloy 3003-O of the plate was modelled as isotropic with elastic-plastic characteristics. The description of the material characteristic of the attenuator was made by means of the Johnson-Cook elastic-plastic law. The material constitutive law of the Al 3003 plates has been implemented in a user-defined subroutine UMAT. The foam core was modelled as a crushable foam material. The finite element results showed a good correlation to the experimental data in terms of contact-force histories, energy histories, absorbed energy, and failure of the sandwich composite was observed between the experimental data.
\end{abstract}

Keywords: Dynamic response, Impactor Shape, Sandwich Composite Plate, Low Velocity Impact, Finite Element Analysis, Damage Analysis.

Corresponding author. Tel.:+90 5442524519. Fax: +90 3642254533.

E-mail address:alikursun@hitit.edu.tr (A. Kurşun) 


\section{Introduction}

Structural sandwich composite materials can be effectively used as a suitable alternative of structural materials in vehicular or aircraft body. Structural design of composite parts has already passed the so-called "replacement phase" and in a number of applications moves toward a "design phase" with a complete redesign of the part in order to take advantage of the customs of this class of materials. However, impact design of composite material structures is still in the early stage of the "demonstrative phase": the designer is still trying to confirm whether some parts could be constructed with a composite material as energy absorber or not. In other way, upon impact, a series of physical phenomena takes place: elastic, shock, and plastic wave propagation, fracture and fragmentation, perforation, etc. Civil and military applications require designing high performance and high energy absorbing materials and structures. For example, in the aerospace industry, new composite wing structures resisting hail and bird impacts are of relevance. Designing energy absorbing materials is challenging since various mechanisms - wave propagation, dynamic cracks, and delamination, thermal effects, dislocation generation, growth, and motion, etc. - are acting concurrently, at different material scales, and intertwined during impact. The sandwich composite materials which have high strength with respect to weight ratio offer a wide range of applications in transportation engineering industries such as automotive, aerospace, marine, and civil engineering. In those applications, composites might be exposed to impacts from foreign objects, such as drop of tools during their life-time of service or operations of assembly and maintenance. These impacts can cause local deflection of the face sheet, delamination, and nucleation of interfacial cracks. These damages may extend during their life-time of service, possibly causing a catastrophic failure of the sandwich composite plate. The impactor shapes may affect impact response of sandwich plate and failure. Therefore, it is necessary to determine the effect of impactor shapes on the impact response of sandwich composite plate.

Recently, numerous researchers have been studying the impact response of composite laminate [1-13]. The previous work can be classified into three categories: (1) impact response of composite laminates, (2) damage characterization, and (3) contact mechanism in composite structures by impact load.

Zhou et al. [6] investigated the parameters effect on the low velocity impact response of foambased sandwich panels using experimental and numerical method and noted that the sandwich panels is strongly dependent on the properties of the foam core. Suvorov and Dvorak [14] improved damage resistance of sandwich plates using a compliant and compressible 
elastomeric foam (EF), and a stiff and incompressible polyurethane (PUR), together with the

same face sheet and core materials. Their findings showed that the PUR interlayer reduces both local deflections of the face sheet and overall, and also the local compression of the foam core and the residual stresses left after unloading.

A relatively small number of researchers have considered the effect of different impactor shapes under low-velocity conditions. Wang et al. [7] experimentally and numerically studied impact energy, impactor diameter, and sandwich panel configuration parameters, such as foam core thickness and face sheet thickness on the impact behaviour and resulting impact damage states. Mitrevski et al. [4] examined the effect of impactor shape on the impact response of thin woven carbon/epoxy laminates experimentally. They reported that the different impactor shapes have great effects on damage mechanisms. Sevkat et al. [15] studied the effect of impactor shapes on the impact response of two hybrid composites with same amount of glass and graphite fabric but with different lay-up sequences. Their results show that impactor with larger contact surface produced higher maximum force, bigger delamination between hybrid layers and shorter contact duration. Icten et al. [16] investigated the effect of impactor diameter on the impact response of woven glass-epoxy laminates, the results show that the projectile diameter highly affects the impact and Compression After Impact (CAI) response of composite materials. The low-velocity impact properties and impact damage response of foam sandwiched composite with different ply angle face sheets had been studied experimentally and numerically by Ramadan et al. [17]. Kurşun et al. [18] investigated experimentally and numerically the effect of biaxial preloading on the low velocity impact performance of E-glass/epoxy-laminated composite plates.

In the literature, there is a scarcity of information on the effect of impactor shapes on the impact response of sandwich composite plates, and thus better data on the response to low-velocity impacts of sandwich structures are needed.

The objective of our current research was to determine the influence of impactor shapes on the low velocity impact performance of aluminium sandwich composite plates and compare the results by experimental and numerical study. Experimental tests were performed using drop weight test machine, samples were impacted using steel conical, ogival, hemispherical and flat impactors, all $12 \mathrm{~mm}$ in diameter, for different initial impact energies of 29.43J and 44.15J. A three dimensional non-linear finite element model was developed for simulating the impact behaviour of sandwich composite plate and the ABAQUS/Explicit commercial program was used. The finite element results showed a good correlation to the experimental data in terms of force and energy-time graph or failure in composite plate. 


\section{Materials and methods}

\subsection{Materials and specimen}

As a test sample, symmetrical aluminium-thermoplastic sandwich plates are considered with four millimeter thickness and dimension 150x150mm. These plates were manufacturing by isothermal compression moulding shown in figure 1. In this moulding procedure, the bottomupper plates and foam is inserted into mould in cold state. And then the whole structure is compressed under thermal and mechanical loads. After consolidation of the part, the mould is open and the sandwich removed [19].

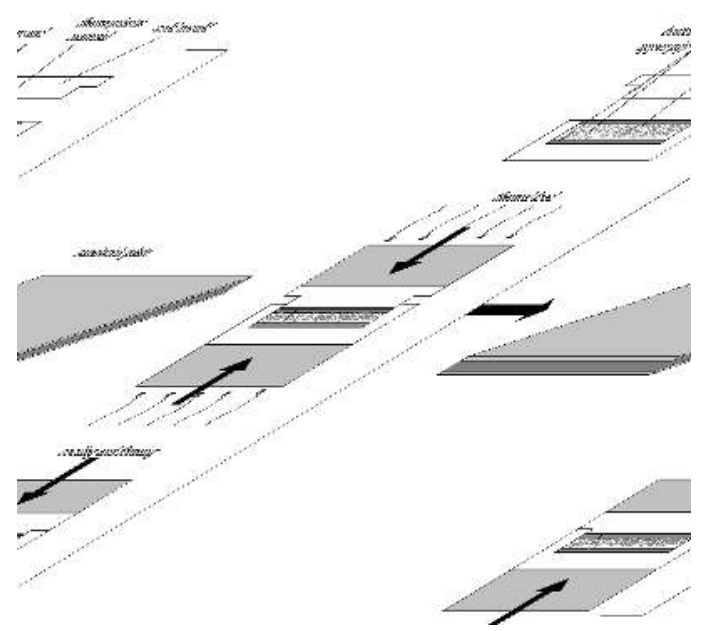

Figure 1: Processes for aluminium-thermoplastic sandwich manufacturing: isothermal compression moulding.

Properties of aluminium-thermoplastic sandwich composite are given in Table 1.

Table 1. Properties of sandwich composite plate

\begin{tabular}{lcc}
\hline Properties & & Unit \\
\hline Thickness & 4 & $\mathrm{~mm}$ \\
Density & 1.35 & $\mathrm{~g} / \mathrm{cm}^{3}$ \\
Weight & 5.49 & $\mathrm{~kg} / \mathrm{m}^{2}$ \\
Tensile strength & 48.3 & $\mathrm{MPa}$ \\
Yield strength & 43.2 & $\mathrm{MPa}$ \\
Elongation rate & 0.15 & \\
Young's modulus & 44 & $\mathrm{MPa}$ \\
\hline
\end{tabular}




\subsubsection{Drop-weight impact tests}

Low-velocity impact tests were conducted using a guided drop-weight test machine developed at Dumlupinar University shown in Fig. 2.

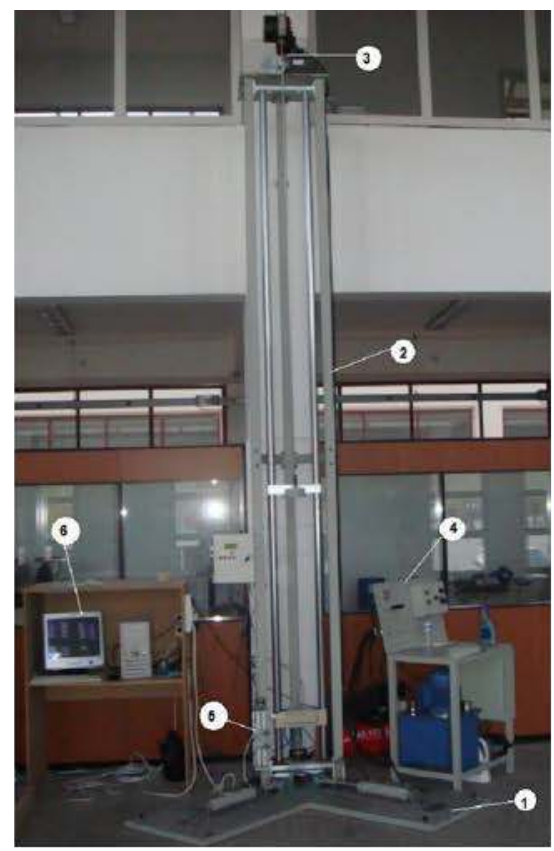

Figure 2: Drop-weight test machine developed at Dumlupinar University: 1-L shape table, 2weight drop tower, 3- lift engine, 4-control unit, 5-reboun breaking system, 6- data acquisition unit.

A specially designed braking system was used to ensure that the impactor hit the specimen only once. The rebound breaks system shown in figure 3. Two optic sensors, a flag, weight holder, two pneumatic pistons, a solenoid valve, and a compressor are used in the system.

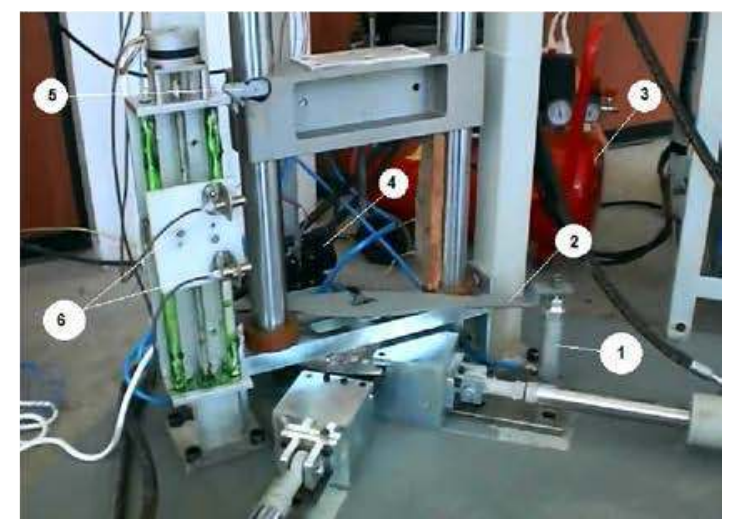

Figure 3: Rebound breaking system; 1-pneumatic piston, 2- weight holder, 3- compressor, 4solenoid valve, 5-flag, 6- optic sensors. 
Fig. 4 shows different shapes of impactor parts used in this work. The impactor consists of two parts, a rod, and nose which can be changed. Four steel nose shapes were used in the experiments, flat, hemispherical, ogival and conical, all $12 \mathrm{~mm}$ in diameter.

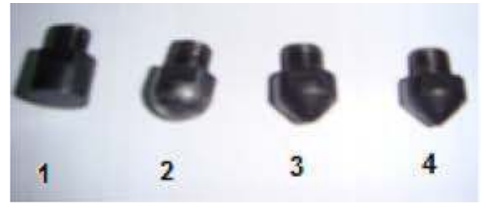

a)

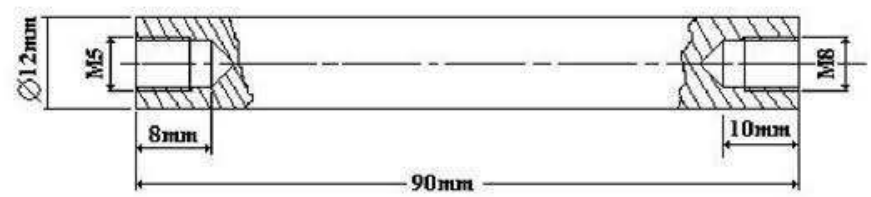

b)

Figure 4 a) Head shapes; 1-flat, 2-hemispherical, 3-ogival and 4-conical, b) Impactor rod drawing

Impacts were applied in the middle points of the specimens and specimens were clamped from four sides before impact. Three experiments were conducted for each condition and the average values were taken as reference. Firstly, force-time graph was created through the data obtained from the force sensor and then the other graphs were obtained through the calculation method. A typical graph related to the energy vs time is given in Fig. 5. Here, different parts of the energy levels are shown after the drop weight test performed from 1meter with only one impact event. The graph is designed for imperforated specimen.
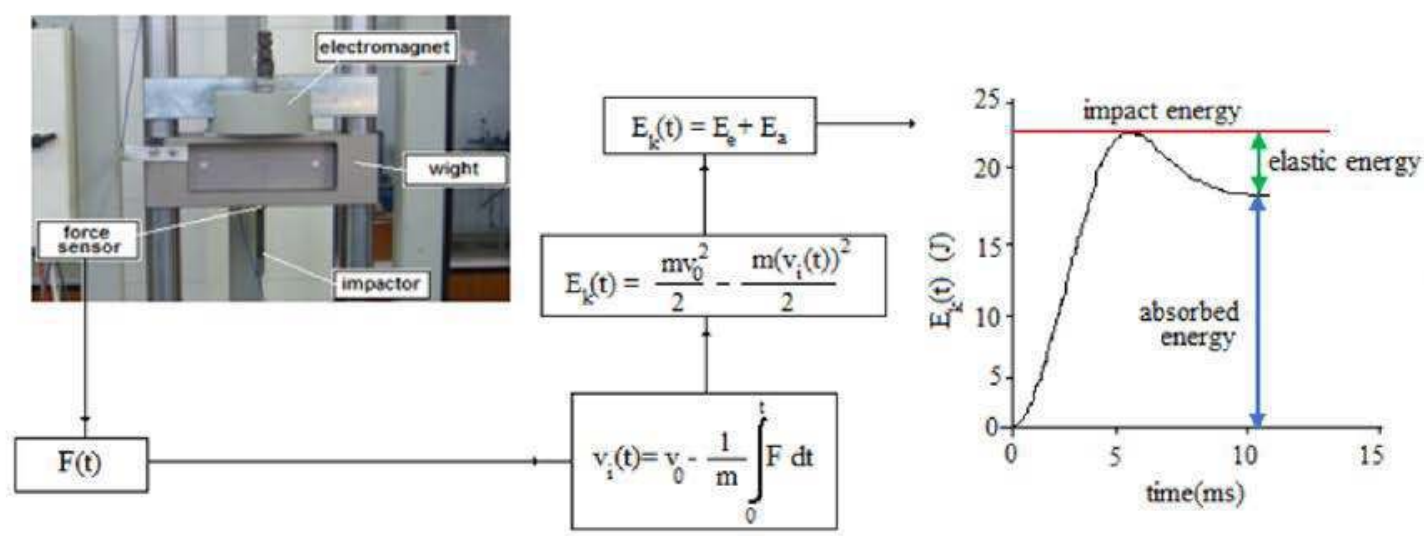

Figure 5: Impact energy level, absorbed energy, and elastic energy [1].

Kinetic energy $E_{k}(t)$, which will occur when an object with the mass $m$ (impactor + weight) hits a sandwich composite plate at a velocity of $\mathrm{v}_{0}$, could be represented as follows: 


$$
\mathrm{E}_{\mathrm{k}}(t)=\frac{m v_{0}^{2}}{2}=\frac{m\left[v_{i}(t)\right]^{2}}{2}
$$

Velocity values in relation to the impactor were obtained through the software in the control centre of the braking system. Besides, the velocity value in relation to the impactor can be represented through the following formula by using the F force value, which is experimentally obtained:

$$
v_{i}(t)=v_{0}-\frac{1}{m} \int_{0}^{t} F d t
$$

Thus, impact energy, which is created in the sandwich composite plate, is obtained as the total of elastic energy $\left(E_{e}\right)$ and absorbed energy $\left(E_{a}\right)$ values. Elastic energy region as shown in the fig. 5 represents the quantity of the rebound energy from the specimen.

Acceleration at $t=t_{i}$ was calculated based on the second law of motion $\left(a_{i}=F_{i} / m\right)$ of Newton [20]. $F_{i}$ value is the value obtained from the force sensor depending on time. Force - time histories are drawn through LabVIEW software in computer during testing. Displacement of the impactor could be easily calculated through a derivative of velocity in relation to time. Thus, a displacement graph is drawn on the basis of the force.

\subsection{Finite element Method}

In order to investigate if the experimentally determined of the influence of impactor shapes on the low velocity impact performance of sandwich composites plates can be represented in a numerical simulation, modelling methodologies of the composite material failure and impactor shapes have been investigated. For this aim, ABAQUS/Explicit is the explicit finite element computer software, which was employed for impact simulation.

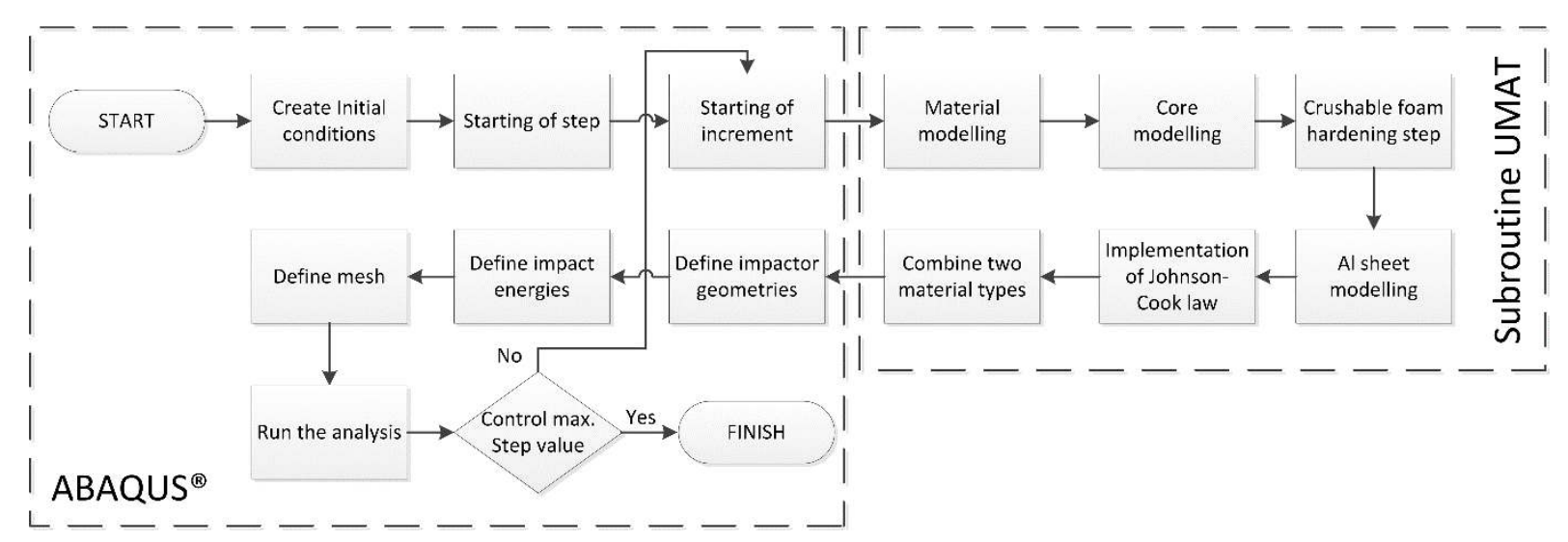

Figure 6: Flow chart of the UMAT subroutine and ABAQUS ${ }^{\circledR}$ software. 
In Fig. 6, the flow of the whole process is illustrated. The sandwich plate was modelled as a four-millimeter thickness and dimension 150x150 mm. The plate clamped at top and bottom rectangular edges to simulate the clamped condition with different impactor geometries in the test machine, as shown in Fig. 4. Interfaces between face sheets and foam core were undamaged subjected to low velocity impact process. The face sheets were meshed with linear reduced integration shell elements (S4R). The laminate was represented by a shell element in the through-thickness direction. The foam core was meshed with linear reduced integration solid elements (C3D8R). The top and bottom surfaces were defined as *SPECIAL SKIN SHELL options in the ABAQUS/Explicit, which were assumed to be perfectly bonded to the core material. The contact interaction between the panel and the impactor was modelled by the general contact provided by the ABAQUS software. Impactor shapes are flat, hemispherical, oval and conical steel impactor with diameter $12 \mathrm{~mm}$ was modelled as rigid body. They were meshed with 4-noded linear tetrahedron continuum elements with the Young's modulus of 200GPa and the Poisson's ratio of 0.3 .

The core was modelled as an elastic-plastic material. The elastic part of the response of the core was defined as *ELASTIC ISOTROPIC option with the parameters: Young's modulus and Poisson's ratio. The plastic part of the response of the core material was modelled using the ${ }^{*}$ CRUSHABLE FOAM and the *CRUSHABLE FOAM HARDENING options in the ABAQUS software. The hardening behaviour was defined in terms of uniaxial compression yield; stress versus strain. In order to get the experimental uniaxial compression curve, a uniaxial compression test was carried out for the stress-strain curve as indicated in Fig. 7. These were used as input data in the card *CRUSHABLE FOAM HARDENING. The elastic region of the stress strain curve was determined by the value of the Young's modulus. This was due to the fact that foam materials usually consist of cells which begin to collapse when the stress reaches the yield stress. As the load continues, all the cell walls inside the foam crushed together. A non-linear finite element model is developed for simulating the impact behaviour of sandwich composite specimens and the ABAQUS/Explicit commercial program was used. 


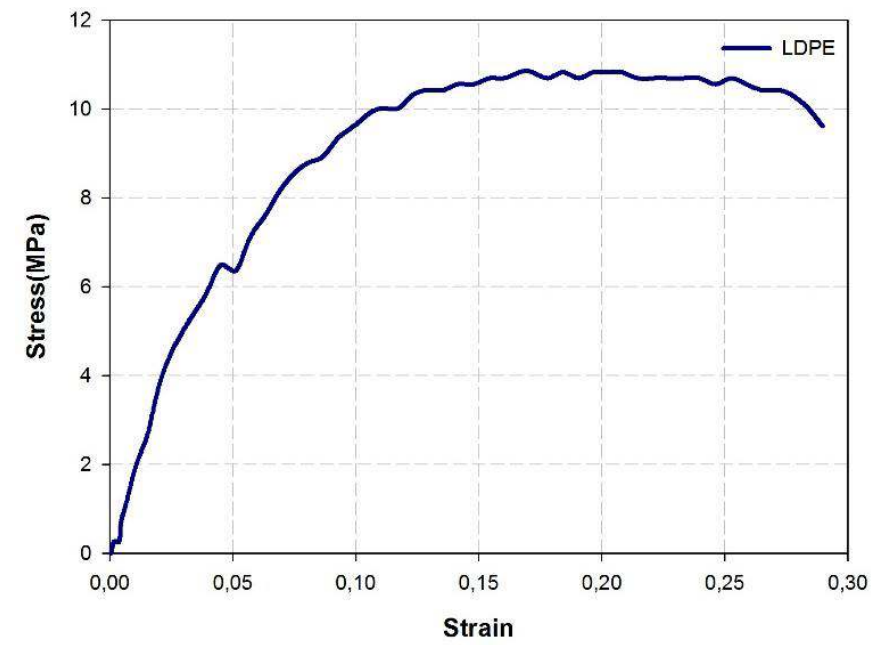

Figure 7: Stress-strain curve for a compression test of LDPE [21].

For this simulation the face sheet material aluminium alloy $3003-\mathrm{O}$ of the plate was modelled as isotropic with elastic-plastic characteristics. The strain hardening behaviour of materials is a major factor in structural response as metal working processes or plastic instability problems. A proper description of strain hardening at large plastic strains is generally imperative. For many plasticity problems, the hardening behaviour of the material is simply characterized by the strain - stress curve of the material. The incremental plasticity theory is generally used in computational methods. Plasticity models are written as rate - dependent or independent. The description of the material characteristic of the attenuator was made by means of the JohnsonCook elastic-plastic law. The material constitutive law of the Al 3003 plates has been implemented in a user-defined subroutine UMAT. The stress vs. plastic strain law is as follows:

$\sigma=\left[a+b\left(\varepsilon_{p}\right)^{n}\right]\left[1+c \ln \left(\frac{\dot{\varepsilon}}{\dot{\varepsilon}_{o}}\right)\right]\left[1-T^{m}\right]$

Where $\sigma$ is flow true stress, $\varepsilon_{\mathrm{p}}$ is plastic strain (true strain), a) is yield stress, b) is hardening modulus, c) is strain rate coefficient, $\dot{\varepsilon}$ ) is strain rate, $\dot{\varepsilon}_{0}$ ) is reference strain rate and $\mathrm{m}$ ) is temperature exponent.

The Johnson-Cook (JC) model assumes that the slope of the flow stress curve is affected by strain hardening, strain rate sensitivity and thermal softening behaviours. Each of these sensitivities is represented by a proper multiplying factor in the constitutive equation. According to this law the material behaves as linear elastic when the equivalent stress is lower 
than the yield stress. For higher value of stress, the material behaviour is plastic. This law is valid for brick, shell, truss and beam elements. Adopted values of above parameter for the aluminium AA 3003-O are given in Table 1. The material properties used during the finite element analysis.

Table 2: Parameters of aluminium alloy 3003-O for The Johnson-Cook Model [22].

\begin{tabular}{lc}
\hline Property & AA 3003-O \\
\hline Density & $2.73 * 10^{-3} \mathrm{~g} / \mathrm{mm}^{3}$ \\
Poisson's ratio & 0.36 \\
Young's modulus & $72600 \mathrm{MPa}$ \\
Yield strength & $42.970 \mathrm{MPa}$ \\
Hardening parameter & $180000 \mathrm{MPa}$ \\
Hardening exponent & 0.210 \\
Strain rate coefficient & 0.00747
\end{tabular}

\section{Results and Discussion}

The low velocity impact damage and contact force to the symmetrical aluminium-thermoplastic sandwich plates was predicted using the FE model for different impactor shapes, and the results compared with experimental result and damage. Experimental tests were performed using drop weight test machine, samples were impacted using steel flat, hemispherical, conical and ogival impactors, all $12 \mathrm{~mm}$ in diameter, for different initial impact energies of $29.43 \mathrm{~J}$ and $44.15 \mathrm{~J}$. Typical force-time histories obtained by experimental test and numerical model for the various impactor shapes and impact energies are shown in Figs. 8. The general shape of the force versus time curves is similar. The time duration of the impact event changes for each shape of indenter. It means that the maximum impact energy is obtained under the $4 \mathrm{~ms}$ for the flat and hemispherical indenters whereas these values are obtained beyond the $4 \mathrm{~ms}(5-6 \mathrm{~ms})$ for the ogival and conical indenter. Additionally, the curve gets narrower with the impactors of larger contact surface. The finding follow the same trends as identified in [4]. As seen in Fig. 8, the contact force increases with the increase of impact energy. Also, it is observed that the contact duration decrease with the increase of the contact surface and impact energy. 


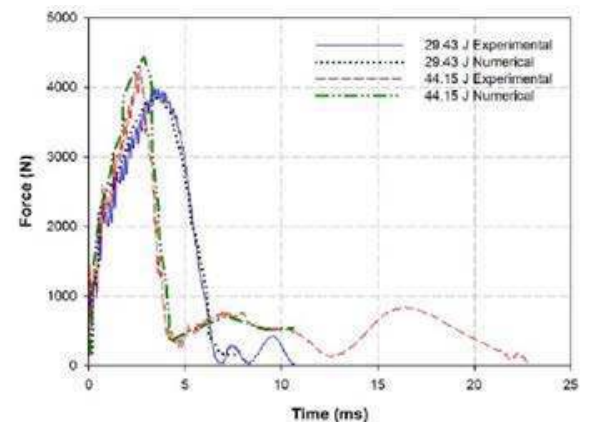

a)

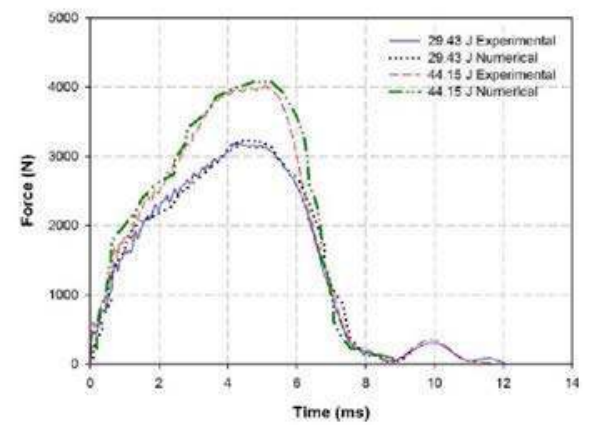

c)

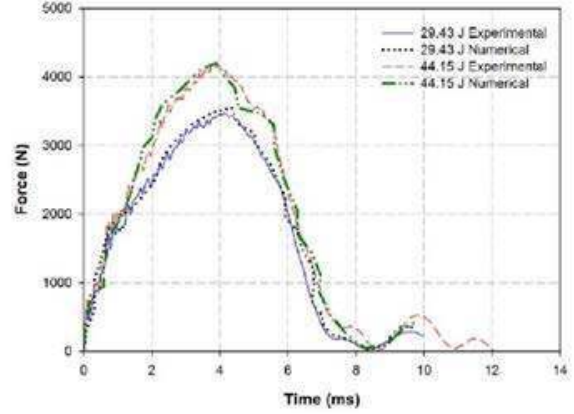

b)

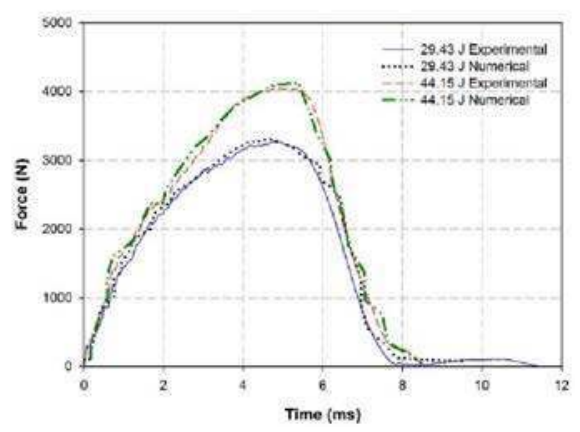

d)

Figure 8: Force - time histories of experimental and numerical impact results for different impact energy with the impactor nose having a) flat, b) hemispherical, c) ogival, and d) conical.

Fig. 9 shows damage evolution and stress counters of FEM simulation from ABAQUS in the aluminium sandwich composite specimens depending on the indenter shapes. All of the results obtained with flat, hemispherical, ogival and conical indenters have been presented as a function of time at a high impact energy level (44.15J). The results clarify that the impactor with larger contact surface can cause very large stress waves distributed the entire surface. However, very similar stress wave distributions concentrate around the contact area for hemispherical, ogival, and conical indenters. 
Flat

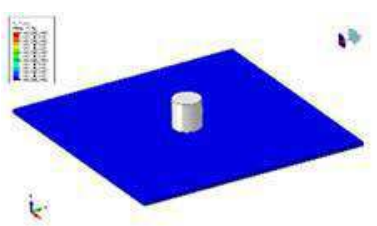

$\mathrm{t}=0 \mathrm{~ms}$

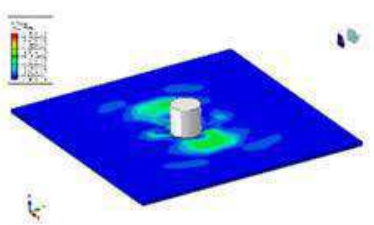

$\mathrm{t}=1.59 \mathrm{~ms}$

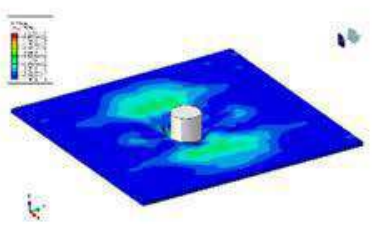

$\mathrm{t}=3.18 \mathrm{~ms}$

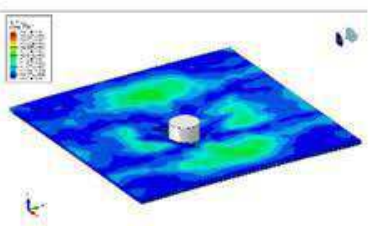

$\mathrm{t}=5.30 \mathrm{~ms}$

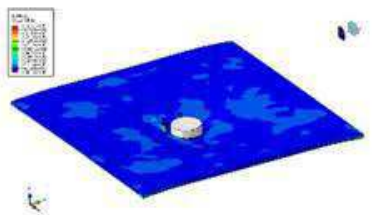

$\mathrm{t}=6.89 \mathrm{~ms}$

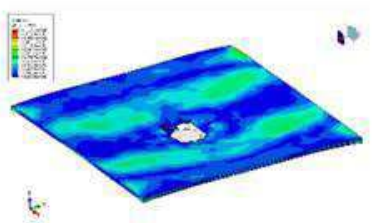

$\mathrm{t}=8.48 \mathrm{~ms}$

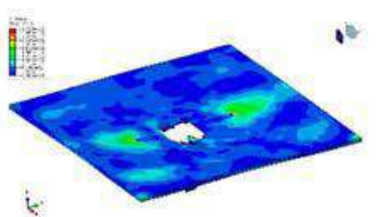

$\mathrm{t}=10.60 \mathrm{~ms}$
Hemispherical

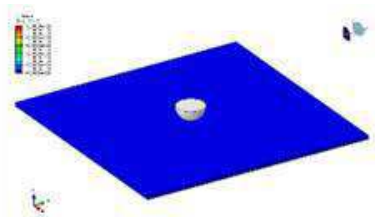

$\mathrm{t}=0 \mathrm{~ms}$

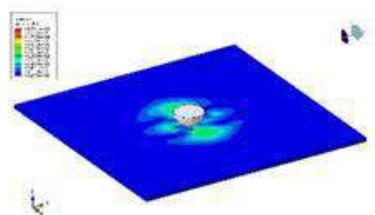

$\mathrm{t}=1.46 \mathrm{~ms}$

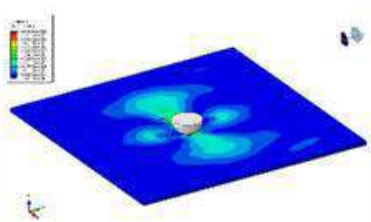

$\mathrm{t}=2.92 \mathrm{~ms}$

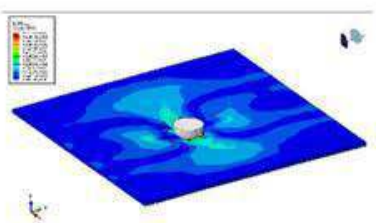

$\mathrm{t}=4.88 \mathrm{~ms}$

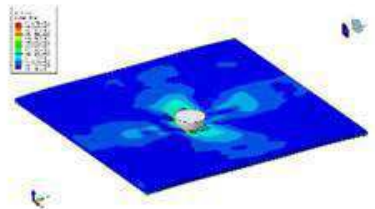

$\mathrm{t}=6.34 \mathrm{~ms}$

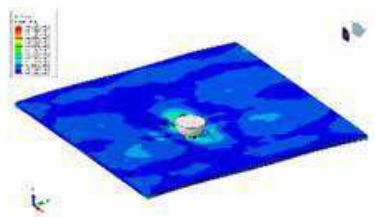

$\mathrm{t}=7.80 \mathrm{~ms}$

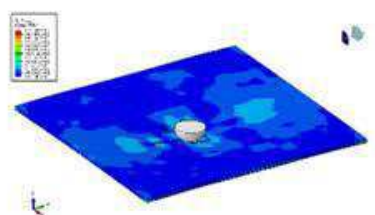

$\mathrm{t}=9.76 \mathrm{~ms}$
Ogival

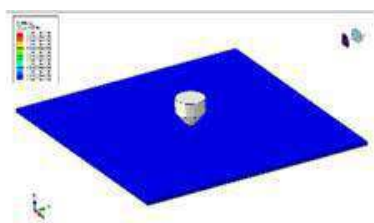

$\mathrm{t}=0 \mathrm{~ms}$

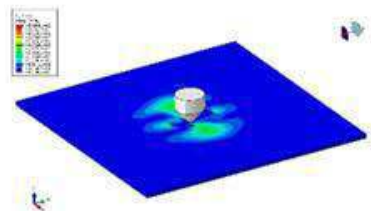

$\mathrm{t}=1.32 \mathrm{~ms}$

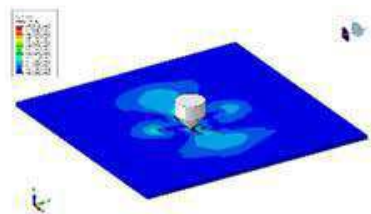

$\mathrm{t}=2.64 \mathrm{~ms}$

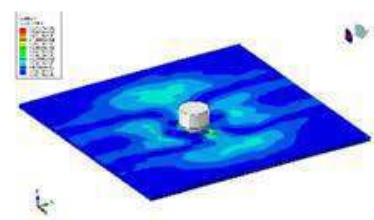

$\mathrm{t}=4.41 \mathrm{~ms}$

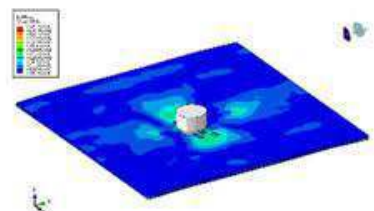

$\mathrm{t}=5.73 \mathrm{~ms}$

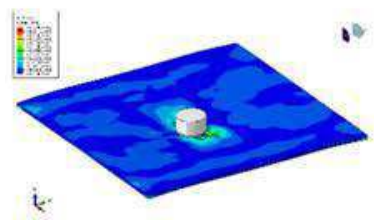

$\mathrm{t}=7.05 \mathrm{~ms}$

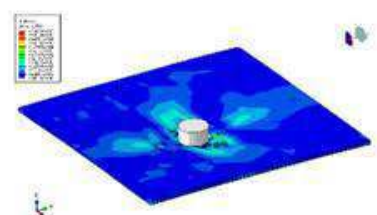

$\mathrm{t}=8.82 \mathrm{~ms}$
Conical

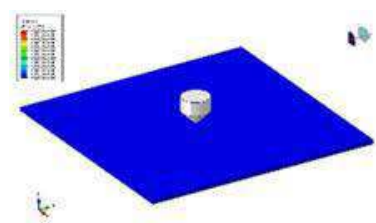

$\mathrm{t}=0 \mathrm{~ms}$

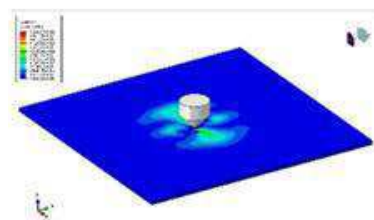

$\mathrm{t}=1.27 \mathrm{~ms}$

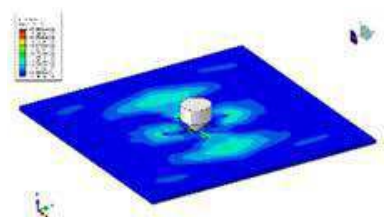

$\mathrm{t}=2.54 \mathrm{~ms}$

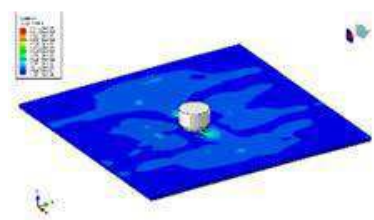

$\mathrm{t}=4.23 \mathrm{~ms}$

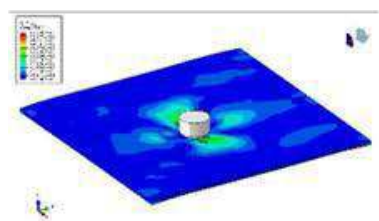

$\mathrm{t}=5.50 \mathrm{~ms}$

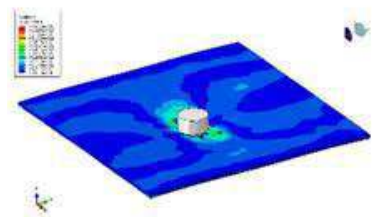

$\mathrm{t}=6.77 \mathrm{~ms}$

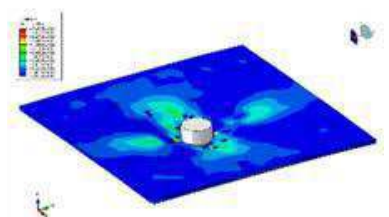

$\mathrm{t}=8.47 \mathrm{~ms}$

Figure 9: Damage evolution and stress counters of FEM simulation for different impactor shapes sandwich composite plate impacted at $44.15 \mathrm{~J}$. 
Fig. 10 shows evolution of the peak stress counters of FEM simulation depending on the different impactor shapes used in the present study. It can also be seen that the amplitude of the oscillations in each curve is variable depending on the shape of the indenter. These aspects were common to all the specimens tested and reflect the interaction of the composite structure and the geometry of the test specimen and clamping device, with the incident indenter.

It can be observed very easily from these figures that the impactor having a larger contact surface produced higher stress, bigger damage and shorter contact duration.

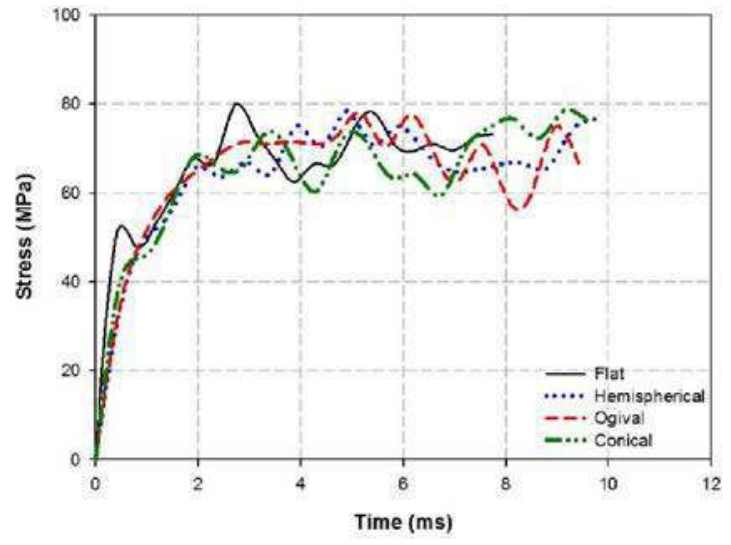

a)

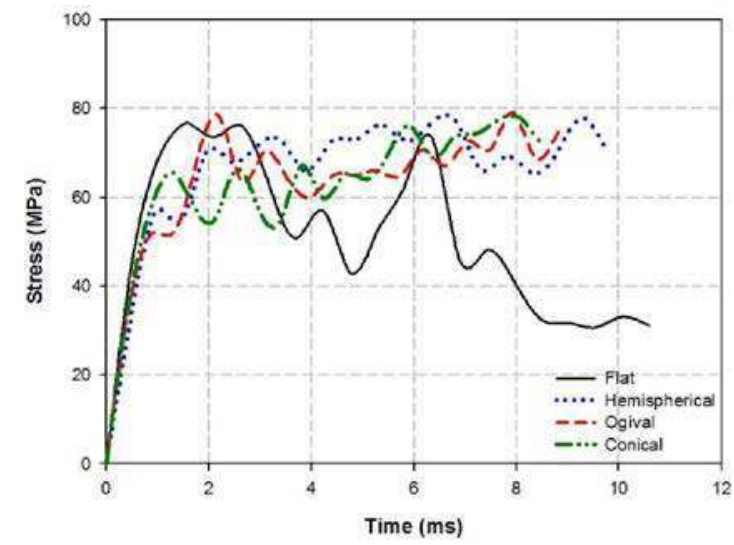

b)

Figure 10: Evolution of peak stress counters of FEM simulation for different impactor shapes a) $29.43 \mathrm{~J}$ and b) $44.15 \mathrm{~J}$.

The experimental and numerical peak contact forces were taken from the force-time histories and the results have been presented in Fig. 11 for different impactor shapes. Given the comparisons with respect to peak contact force, the impactor with larger contact surface produced higher maximum force and shorter contact duration. For the maximum impact energies, the contact force takes maximum value $\left(F_{\exp }=4307,68 \mathrm{~N}\right.$ and $\left.F_{\text {num }}=4430,34 \mathrm{~N}\right)$ for flat impactor nose and minimum $\left(F_{\text {exp }}=4017,28 \mathrm{~N}\right.$ and $\left.F_{\text {num }}=4072,04 \mathrm{~N}\right)$ for ogival impactor nose. All of the experimental and numerical results obtained are very similar. 


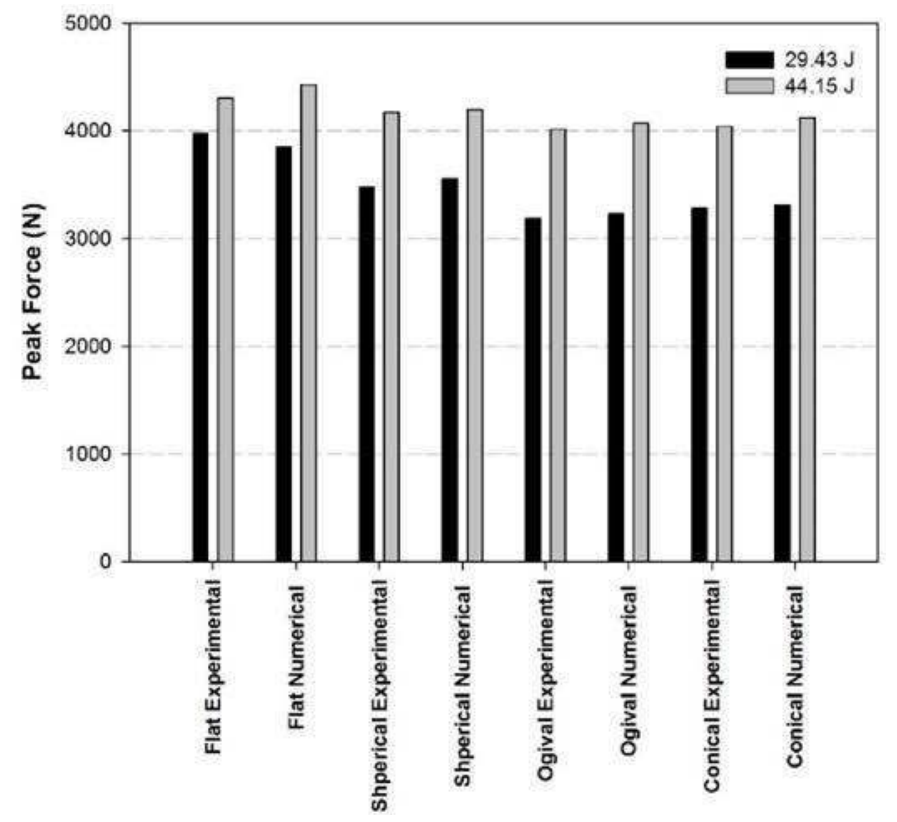

Figure 11: Experimental and numerical peak force values obtained from force - time histories.

The maximum deflection were obtained by integrating the force-time histories and shown in Fig. 12 for different impactor shapes. As seen in Fig. 12, the deflection increases with the decrease of the contact surface. For the same impact energies, the maximum deflection is higher for lower impactor contact surface. For the flat nose and 44.15J, the deflection takes maximum value because of the samples was punched.

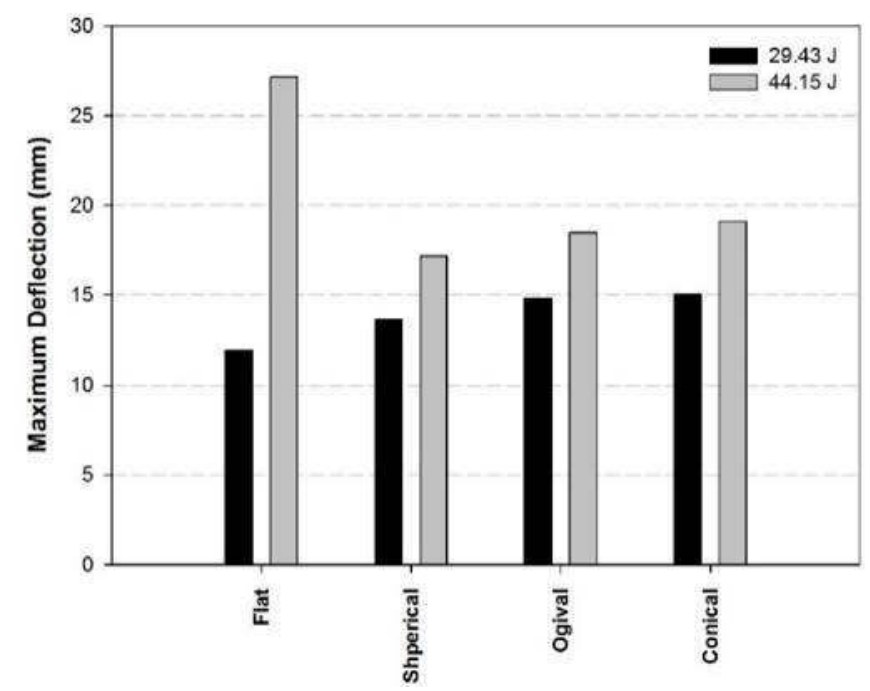

Figure 12: Maximum deflection obtained by integrating the force-time history. 
The energy absorbed by the specimens for the various impactor shapes were shown in Fig. 13, where the specimens impacted by the flat impactor absorb the least energy and the conical impactor the most. When the specimens impacted by the flat impactor nose, the impact damages occurred faster and bigger.

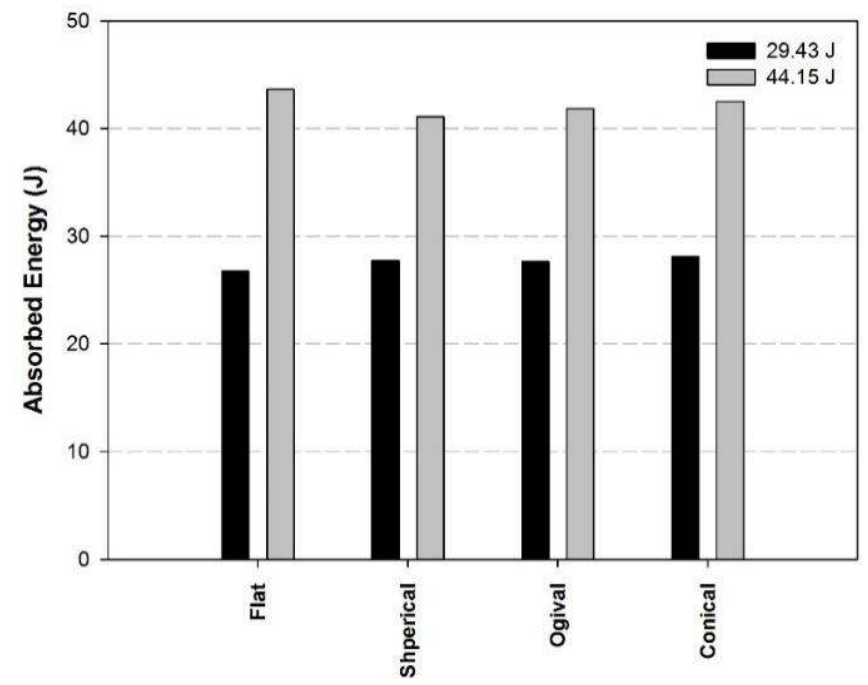

Figure 13: Absorbed energy for different impactor nose shapes

Damaged parts are shown in Fig. 14 as front and rear sides for each tested specimen. In reality, these composites do not exhibit the same fracture behavior. It is always possible to see plastic deformations with very large homogenous distributions in case of hemispherical, ogival and conical shape indenters whereas flat shape indenter give very brittle damage like stamping effect with lower deformation around the contact area. It means that a regular tearing damage occurs after large plastic deformation in case of ogival and conical shape indenters. For example, narrow stressed layers are located around the fracture surfaces mainly around the impact area. Numerical simulations give obvious information about the initiation peak and propagation and fracture directions. The formation of these damage bands is mainly due to the crack crossing over heterogeneities. This behaviour can be observed very often in the structural sandwich based composites. 
Flat

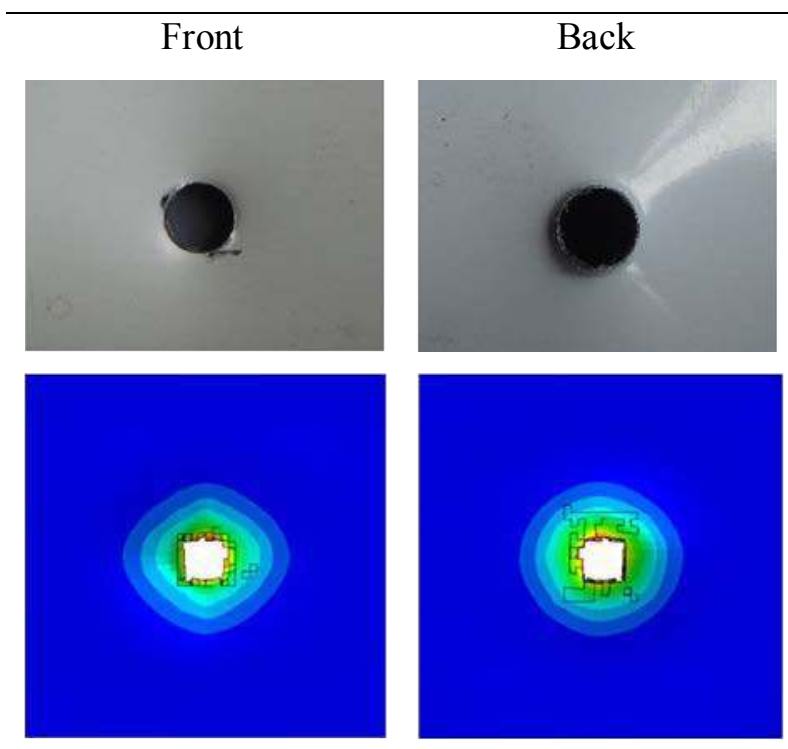

Ogival
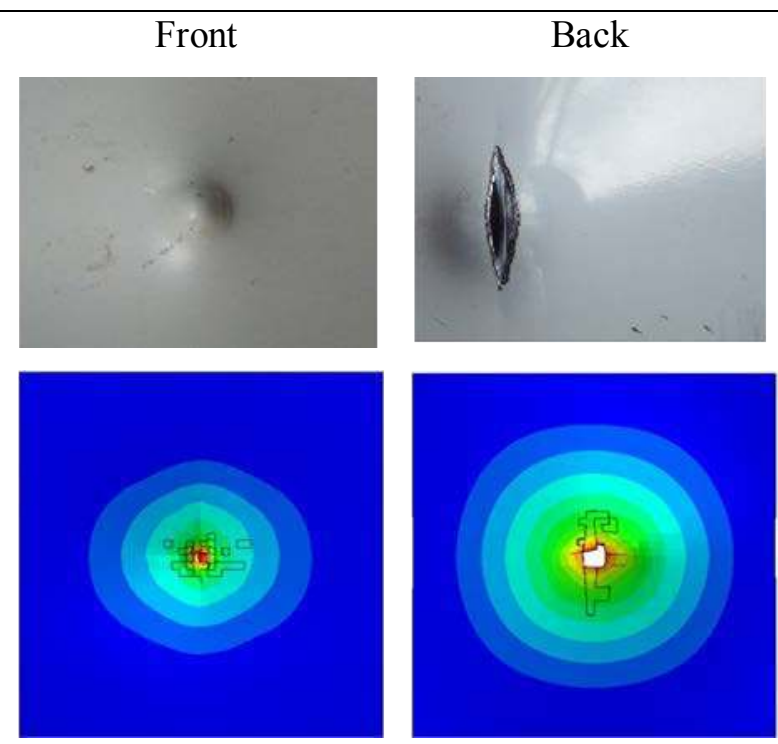

Hemispherical
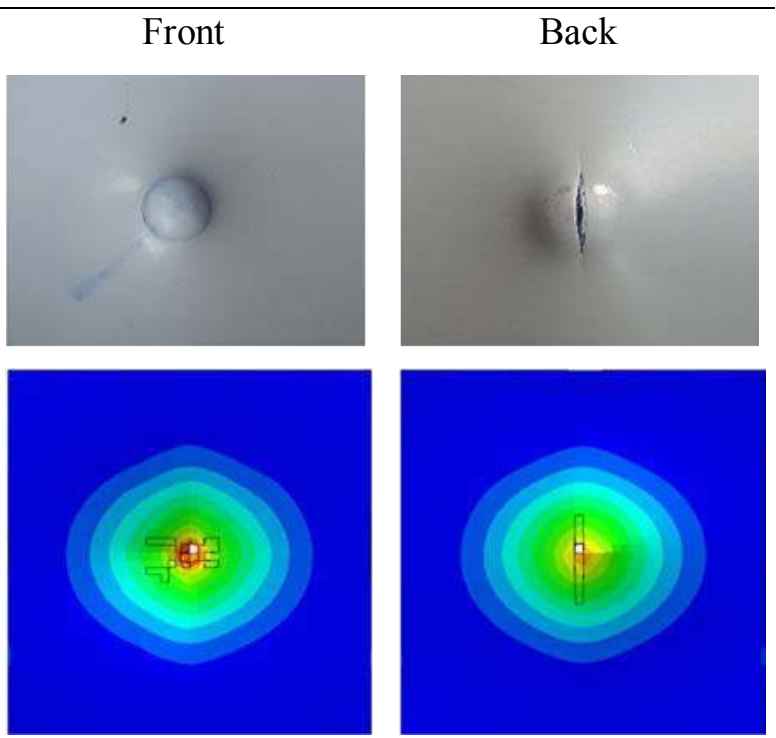

Conical

Figure 14: Comparison of numerical and experimental damage forms obtained at high impact energy level.

\section{Conclusions}

The damage behaviour of aluminum sandwich composite plates subjected to low velocity impact loading has been examined. In another words, a detail experimental and numerical study has been carried out on the influence of indenter shapes on the low velocity impact performance of aluminium sandwich composite plates. The presentation against low energy impact events 
of the sandwich composites tested were dominated by the intrinsic characteristics of these composites

In fact, this type of the experimental setup allows acquiring the impacting running force versus time signals; then the relevant kinematic quantities can be obtained by simple numerical integration of the acceleration history. In fact, the histories of the kinematic quantities and of the contact force at the moment of impact drop weight test have been examined in case of all the four different types of indenters like flat bottom shape, ogival, hemispherical and also conical shape indenters.

Experimental tests were performed using drop weight test machine and all of the test samples were impacted using steel conical, ogival, hemispherical and flat bottom shape indenters with a diameter of $12 \mathrm{~mm}$. Two different initial impact energy levels are used as $29.43 \mathrm{~J}$ and $44.15 \mathrm{~J}$. Some general observations of this study can be summarized as follows:

- Plastic deformations with very large homogenous distributions in case of hemispherical, ogival and conical shape indenters whereas flat shape indenter give very brittle damage like stamping effect with lower deformation around the contact area.

- The indenter with larger contact surface produced higher stress, bigger damage and shorter contact time duration.

- The contact duration decrease with the increase of the contact surface and impact energy.

- The deflection increases with the decrease of the contact surface. For the same impact energy levels, the maximum deflection is higher for lower indenter contact surface.

- The specimens impacted by the flat bottom shape indenter, the impact damages occurred faster and bigger.

- The aluminium and low density polyethylene core can be separated and the possibility of recycling of these materials for the environmental and economic reasons.

\section{Acknowledgment}

The authors would like to thank The Science and Technological Research Council of Turkey (TUBITAK) for the financial support of this work, grant number is $105 \mathrm{M} 195$. 


\section{REFERENCES}

[1] Kursun A, Senel M. Investigation of the Effect of Low-Velocity Impact on Composite Plates with Preloading. Experimental Techniques. 2013;37(6):41-8.

[2] Aslan Z, Karakuzu R, Okutan B. The response of laminated composite plates under low-velocity impact loading. Composite Structures 2003;59 119-27.

[3] Whittingham B, Marshall IH, Mitrevski T, Jones R. The response of composite structures with prestress subject to low velocity impact damage. Composite Structures. 2004;66(1-4):685-98.

[4] Mitrevski T, Marshall IH, Thomson RS, Jones R. Low-velocity impacts on preloaded GFRP specimens with various impactor shapes. Composite Structures. 2006;76(3):209-17.

[5] Malekzadeh K, Khalili MR, Mittal RK. Response of composite sandwich panels with transversely flexible core to low-velocity transverse impact: A new dynamic model. International Journal of Impact Engineering. 2007;34(3):522-43.

[6] Zhou J, Hassan MZ, Guan Z, Cantwell WJ. The low velocity impact response of foam-based sandwich panels. Composites Science and Technology. 2012;72(14):1781-90.

[7] Wang J, Waas AM, Wang $\mathrm{H}$. Experimental and numerical study on the low-velocity impact behavior of foam-core sandwich panels. Composite Structures. 2013;96:298-311.

[8] Tan ZH, Luo HH, Long WG, Han X. Dynamic response of clamped sandwich beam with aluminium alloy foam core subjected to impact loading. Composites Part B: Engineering. 2013;46:39-45.

[9] Schubel PM, Luo J-J, Daniel IM. Low velocity impact behavior of composite sandwich panels. Composites Part A: Applied Science and Manufacturing. 2005;36(10):1389-96.

[10] Palazotto AN, Herup EJ, Gummadi LNB. Finite element analysis of low-velocity impact on composite sandwich plates. Composite Structures 2000(49):209-27.

[11] Manes A, Gilioli A, Sbarufatti C, Giglio M. Experimental and numerical investigations of low velocity impact on sandwich panels. Composite Structures. 2013;99:8-18.

[12] Malekzadeh Fard K, Khalili SMR, Forooghy SH, Hosseini M. Low velocity transverse impact response of a composite sandwich plate subjected to a rigid blunted cylindrical impactor. Composites Part B: Engineering. 2014;63:111-22.

[13] Feng D, Aymerich F. Damage prediction in composite sandwich panels subjected to low-velocity impact. Composites Part A: Applied Science and Manufacturing. 2013;52:12-22.

[14] Suvorov AP, Dvorak GJ. Enhancement of low velocity impact damage resistance of sandwich plates. International Journal of Solids and Structures. 2005;42(8):2323-44.

[15] Sevkat E, Liaw B, Delale F. Drop-weight impact response of hybrid composites impacted by impactor of various geometries. Materials \& Design. 2013;52:67-77.

[16] Icten BM, Kıral BG, Deniz ME. Impactor diameter effect on low velocity impact response of woven glass epoxy composite plates. Composites Part B: Engineering. 2013;50:325-32.

[17] Ramadan M, Fa Z, Baozhong S, Bohong G. Finite element analyses of low-velocity impact damage of foam sandwiched composites with different ply angles face sheets. Materials and Design 2013;47 189-99.

[18] Kurşun A, Şenel M, Enginsoy HM. Experimental and numerical analysis of low velocity impact on a preloaded composite plate. Advances in Engineering Software 2015;90 41-52.

[19] Olivier S, Christophe B, Patricia K. All-thermoplastic Composite Sandwich Panels - Part I: Manufacturing and Improvement of Surface Quality. Journal of Sandwich Structures and Materials 2004;6:399-421.

[20] Uyaner M, Kara M. Dynamic Response of Laminated Composites Subjected to Low-velocity Impact. JOURNAL OF COMPOSITE MATERIALS. 2007;41:2877-96.

[21] Salih SE, Hamood AF, alsalam AHA. Comparison of the Characteristics of LDPE : PP and HDPE : PP Polymer Blends. Modern Applied Science. 2013;7:33-42

[22] Saulo AdCC, Carlos AdSC, Márcio ES. Numerical Study on Incremental Sheet Forming Applied on An Impact Attenuator Model. 22nd International Congress of Mechanical Engineering (COBEM 2013) November 3-7, 2013 Ribeirão Preto, SP, Brazil: ABCM; 2013. p. 6077-86. 